\title{
Trends in family planning and counselling for women with sickle cell disease in the UK over two decades
}

\author{
Asma A Eissa, ${ }^{1}$ Susan M Tuck, ${ }^{2}$ Khadija Rantell, $^{3}$ Daniel Stott ${ }^{4}$
}

${ }^{1}$ Clinical Research Fellow, Department of Obstetrics and Gynaecology, Royal Free Hospital, London, UK ${ }^{2}$ Consultant and Senior Lecturer, Department of Obstetrics and Gynaecology, Royal Free Hospital, London, UK ${ }^{3}$ Medical Statistician, University College London, London, UK ${ }^{4}$ Clinical Fellow in Obstetrics and Gynaecology, King's College Hospital, London, UK

\section{Correspondence to} Miss Susan M Tuck, Department of Obstetrics and Gynaecology, Royal Free Hospital, Pond Street, London NW3 2QG, UK susan.tuck@nhs.net

Received 14 August 2013 Revised 11 February 2014 Accepted 15 April 2014 Published Online First 23 May 2014
CrossMark

\footnotetext{
To cite: Eissa AA, Tuck SM, Rantell K, et al. J Fam Plann Reprod Health Care 2015:41:96-101.
}

\begin{abstract}
Background Pregnancies in women with sickle cell disease (SCD) are known to have high rates of maternal and fetal mortality and morbidity. Given these pregnancy-associated problems for women with SCD, advice both about pregnancy planning and about effective contraception are of paramount importance. This study sought to discover the contraception methods used by women with SCD, what complications women with SCD encounter with contraception, and their experiences of pre-pregnancy counselling and pregnancy planning, and how such issues may have changed over the past two decades.

Method The study was a multicentre, interviewbased, cross-sectional study. Interviews were carried out with 102 women with SCD, in north and central London during 2010, concerning their current and previous contraceptive use, their pregnancy history, their menstrual history, and the advice they received concerning pregnancy planning and contraception. Patient information was anonymised and ethical approval was obtained. These data were compared with data from a similar study undertaken in 1993.
\end{abstract}

Results There were significant differences in a number of key areas: the number of unplanned pregnancies decreased from $64 \%$ in 1993 to $53 \%$ in 2010 . The number of women with SCD who were advised not to become pregnant also fell, from $36 \%$ to $15 \%$. The use of combined oral contraceptive pills declined, from $45 \%$ of the women in 1993 to $31 \%$ in 2010 . Conversely the use of depot medroxyprogesterone acetate contraception (DMPA) and the levonorgestrel intrauterine system (LNG-IUS) both increased. Conclusions Significant changes in the contraceptive methods used by women with SCD are demonstrated in the London population. LNG-IUS use in SCD has not been investigated before. There has been an encouraging decrease
Key message points

- There remains an extremely high number of unplanned pregnancies among women with sickle cell disease $(S C D)$, reflecting the need for these women to have access to well-informed advice about contraception.

- The use of combined oral contraceptive pills is declining among women with $S C D$, while the use of depot medroxyprogesterone acetate contraception has been increasing in this cohort.

- More women with SCD are now using newer contraceptive methods such as the levonorgestrel intrauterine system, with very few reported complications.

in the number of women with SCD who are advised not to become pregnant, perhaps reflecting an improvement in their overall health. Although the number of unplanned pregnancies has fallen, it remains high - emphasising the continuing need for women with SCD to have access to informed advice about pregnancyassociated issues and contraception.

\section{BACKGROUND}

Sickle cell disease (SCD) is an inherited, incurable abnormality of haemoglobin, characterised by multiple acute episodes and chronic complications and a shorter-thanaverage life expectancy. There are an estimated 12500 people with SCD in the UK. ${ }^{1}$ Pregnancies in women with SCD have a high rate of maternal and fetal mortality and morbidity. $^{2-5}$

The maternal death rate in women with SCD in the UK is approximately 
$1.6 \%$, in contrast to the overall national pregnancy-related death rate in the UK of $0.01 \% .^{6}$ The perinatal mortality rate (stillbirths and deaths in the first week after birth) in SCD is approximately 60/ 1000 compared with the overall rate in the UK of 7.9/ $1000 .^{4}$ Serious complications such as sickling crises occur in $40 \%$ of pregnancies. ${ }^{5}$ These significantly increased maternal and fetal risks necessitate effective family planning advice in order that women with SCD, recognising the problems in pregnancy associated with SCD, are able to optimise the timing of, and preparation for, their pregnancies. However, this clear need is unfortunately handicapped by the extreme paucity of evidence-based contraceptive advice for women with $\mathrm{SCD}^{7}$ resulting in the family planning advice given to these women generally being negative and unhelpful.

Contraceptive choices for women with SCD are complicated by three main areas of concern: first, the combined oral contraceptive pill (COC) is associated with an increased risk of venous thromboembolism (VTE). ${ }^{8-10}$ SCD is known to be a prothrombotic condition. Thrombosis is triggered by deformed red blood cells whose abnormal cell membrane has lost its natural phospholipid asymmetry, hence becoming stickier and adhering to the endothelium, forming a port to which prothrombotic enzymes dock. Thrombosis is also more likely with SCD due to the presence of free circulating haemoglobin (the result of red cell breakdown), the occurrence of chronic inflammatory reactions, and slow microcirculation. $^{11} 12$ It has therefore been assumed that these two risks would be additive or indeed multiplicative. This presumed increased thrombosis risk is theoretical and has not been demonstrated in any well-designed studies. ${ }^{7}$ Second, perhaps because of this concern over the thrombotic risk of COCs, there is a tendency to advise SCD women to use progestogen-only forms of contraception, either oral progestogen-only pills (POPs), or long-acting reversible contraceptives (LARCs), which have a lower VTE risk in the general population. ${ }^{13-16}$ Due to the need to adhere to a strict schedule for effective use, in practice the failure rate with traditional POPs is believed to be higher than with COC use, ${ }^{17}$ although this is not a problem with desogestrel-only pills. Despite the high efficacy of depot medroxyprogesterone acetate (DMPA), this contraceptive method commonly results in amenorrhoea, which some women find unacceptable. Both POPs and LARCs frequently cause irregular vaginal bleeding, which is the commonest cause of discontinuation. ${ }^{18-20}$ Third, standard copper-containing intrauterine contraceptive devices (IUDs) are often regarded as inappropriate for women with SCD because of the increased menstrual blood loss associated with their use, which would exacerbate the chronic anaemia associated with SCD and potentially provoke acute sickling episodes.
The UK Medical Eligibility Criteria for Contraceptive Use (UKMEC) in 2009 stated that the use of COC in SCD is UKMEC Category 2 (i.e. the benefits of use outweigh the risks) and the use of progestogen-only contraception (POC) is Category 1 (i.e. no restriction on their use). ${ }^{21}$ However this recommendation is based on evidence that pregnancy carries many hazards in women with SCD, and not on evidence specifically supporting their safety.

This study aimed to answer the following questions: what is the experience of pregnancy planning for women with SCD, what guidance do they receive, and what methods of contraception are they using? The study also aimed to ascertain the proportion of these women's pregnancies that were unplanned. The survey provided some limited further data on what complications women with SCD experience with specific contraceptive methods, and also looked at their menstrual histories and the counselling they received about the reproductive health aspects of their disease.

These data were compared with data obtained from a similar survey conducted in $1993^{22}$ to explore how the knowledge and attitudes of women with SCD and that of their health care professionals might have changed over time.

\section{METHODS}

This was a multicentre, interview-based, crosssectional study involving four acute hospital trusts and two Sickle Cell and Thalassaemia Centres in north and central London. The study participants were identified from lists of patients attending these services, over a 12-month period from 2009 to 2010. The inclusion criteria were women with SCD (haemoglobin SS, SC and S $\beta$-thalassaemia), aged 18 years and over, who consented to be interviewed.

The participants were interviewed at their local hospital in confidence by the principal researcher (AAE), using a structured, validated questionnaire. Each interview lasted about 30 minutes. Patient information was anonymised to preserve confidentiality and to comply with the Data Protection Act 1978. Data were obtained on demographic and clinical characteristics, contraceptive methods used and side effects experienced. In addition, information was ascertained about past contraception, pregnancy history and the health care advice the women received regarding pregnancy planning.

The results are summarised using the mean and standard deviation, or median and range. Categorical data were summarised using count and percentages. The 95\% confidence intervals for the differences between proportions or means are presented, where appropriate. The contraceptive complications are reported as percentages in woman-years of use (the summation of duration of use by individual women expressed in years). These data are compared with a similar survey conducted in 1993 from the same 
hospitals and Haemoglobinopathy Centres in north London, using the Chi square $\left(\chi^{2}\right)$ test or logistic regression, as appropriate. All analyses were carried out using Stata V.11. ${ }^{23}$ Consent to verify a reported serious illness, such as an episode of thrombosis requiring hospital admission, investigation and treatment, was sought and the researcher viewed the woman's hospital records, in order to obtain clinical details of any such complications. The inability to verify such details was a drawback to the 1993 survey.

The study received ethical approval from the Cambridge 4 Research Ethics Committee on behalf of the National Multi-Centre Research Ethics Committee. This survey was supported by the multiprofessional and multidisciplinary membership of the UK Forum for Haemoglobin Disorders, which includes patient representatives from the Sickle Cell Society.

\section{RESULTS}

A total of 114 women were invited to participate and 102 consented to do so; 75 of them carry haemoglobin SS type, 19 haemoglobin SC and eight have S $\beta$-thalassaemia. In the 1993 survey, 156 women consented to participate, of whom 102 had haemoglobin SS, 42 haemoglobin SC and 12 S $\beta$-thalassaemia.

The mean age at interview was 34.6 (19-65) years in the 2010 survey, while the mean age in the 1993 survey was 28.7 (17-53) years. Age at menarche was 14 years in the 2010 survey and 15 years in the 1993 survey.

The 102 women surveyed in 2010 had had 150 pregnancies, and there had been 207 pregnancies in the 156 women interviewed in 1993. The unplanned pregnancy rate was $53 \%$ in the 2010 survey compared with $64 \%$ in the 1993 survey. Sixteen (15\%) women in the 2010 survey said they had received advice against pregnancy, compared with 54 (36\%) women in the 1993 survey. The number of women understanding the mode of inheritance of SCD increased from $28 \%$ in the 1993 survey to $88 \%$ in the 2010 survey.

The COCs used by the women in the survey were standard formulations containing 35,30 or $20 \mu \mathrm{g}$ ethinylestradiol, with norethisterone acetate, levonorgestrel, noregestimate or drospirenone progestogens. None of the participants reported use of 'third generation' COCs containing desogestrel or gestodene as the progestogen.

The POPs used were levonorgestrel, norethisterone or desogestrel.

The intrauterine devices (IUDs) used were all standard copper and plastic devices, but the specific design used by each woman was not known.

In the 2010 survey eight (8.7\%) women were using the levonorgestrel intrauterine system (LNG-IUS), with a total of 15 years' use. Six (6.5\%) women were using etonorgestrel subcutaneous implants with a total
Table 1 Trends in the use of contraceptive methods over a period of 17 years

\begin{tabular}{|c|c|c|c|}
\hline Contraceptive & $\begin{array}{l}1993 \\
\text { Count }(\%)\end{array}$ & $\begin{array}{l}2010 \\
\text { Count (\%) }\end{array}$ & $p$ \\
\hline$\overline{C O C}$ & $67 \quad(45 \%)$ & $29(31 \%)$ & \\
\hline $\begin{array}{l}\text { Difference in proportions } \\
(95 \% \mathrm{Cl})\end{array}$ & $14 \% \quad(1-26 \%)$ & & 0.035 \\
\hline DMPA & $(17 \%)$ & $35(38 \%)$ & \\
\hline $\begin{array}{l}\text { Difference in proportions } \\
(95 \% \mathrm{Cl})\end{array}$ & $21 \%(10-32 \%)$ & & $<0.001$ \\
\hline POP & $(20 \%)$ & $14(15 \%)$ & \\
\hline $\begin{array}{l}\text { Difference in proportions } \\
(95 \% \mathrm{Cl})\end{array}$ & $5 \% \quad(4-15 \%)$ & & 0.0325 \\
\hline IUD and IUS & $(19 \%)$ & $2(2 \%)$ & \\
\hline $\begin{array}{l}\text { Difference in proportions } \\
(95 \% \mathrm{Cl})\end{array}$ & $17 \%(10-32 \%)$ & & $<0.001$ \\
\hline
\end{tabular}

$\mathrm{Cl}$, confidence interval; $\mathrm{COC}$, combined oral contraceptive pill; DMPA, depot medroxyprogesterone acetate; IUD, intrauterine device; IUS, intrauterine system; POP, progestogen-only pill.

of 14 years' use. The side effects were minimal. Amenorrhoea was experienced by one woman in each group $(12.5 \%$ and $16.7 \%$, respectively). Irregular bleeding was reported by one woman in each group. There were no reports of VTE in either group, but one woman using an implant had a stroke, and there were no contraceptive failures with either of these methods. The LNG-IUS and the implant were not included in the trend analysis as these methods were not used by any of the women interviewed in the 1993 study (Tables 1 and 2 and Figure 1).

\section{DISCUSSION}

The number of unplanned pregnancies in women with SCD is still unacceptably high, albeit there is some improvement in 2010 compared with the 1993 survey (53\% vs $64 \%)$. The fact that over $50 \%$ of SCD pregnancies are still unplanned in the 2010 survey confirms that there is a continuing unmet need for effective contraceptive advice for this patient group. Further efforts to educate health care professionals about this issue are clearly needed, as well as initiatives to include contraceptive advice in the routine medical care of young women with SCD.

There is a statistically significant declining trend in the use of COCs, which decreased by about one-third from 1993 to 2010, while the use of DMPA has more than doubled over the same period. The authors believe that the studies conducted by De Ceulaer et al. in 1982 and by de Abood et al. in 1997, both of which concluded that DMPA decreases the incidence of painful sickling crises, led to a considerable change in the family planning practice of those looking after women with SCD, with a reversal of the rate of use between COCs and DMPA. ${ }^{24}{ }^{25}$ This trend is opposite to that seen in the general population, where COC use is quoted to be 10 times higher than the use of 


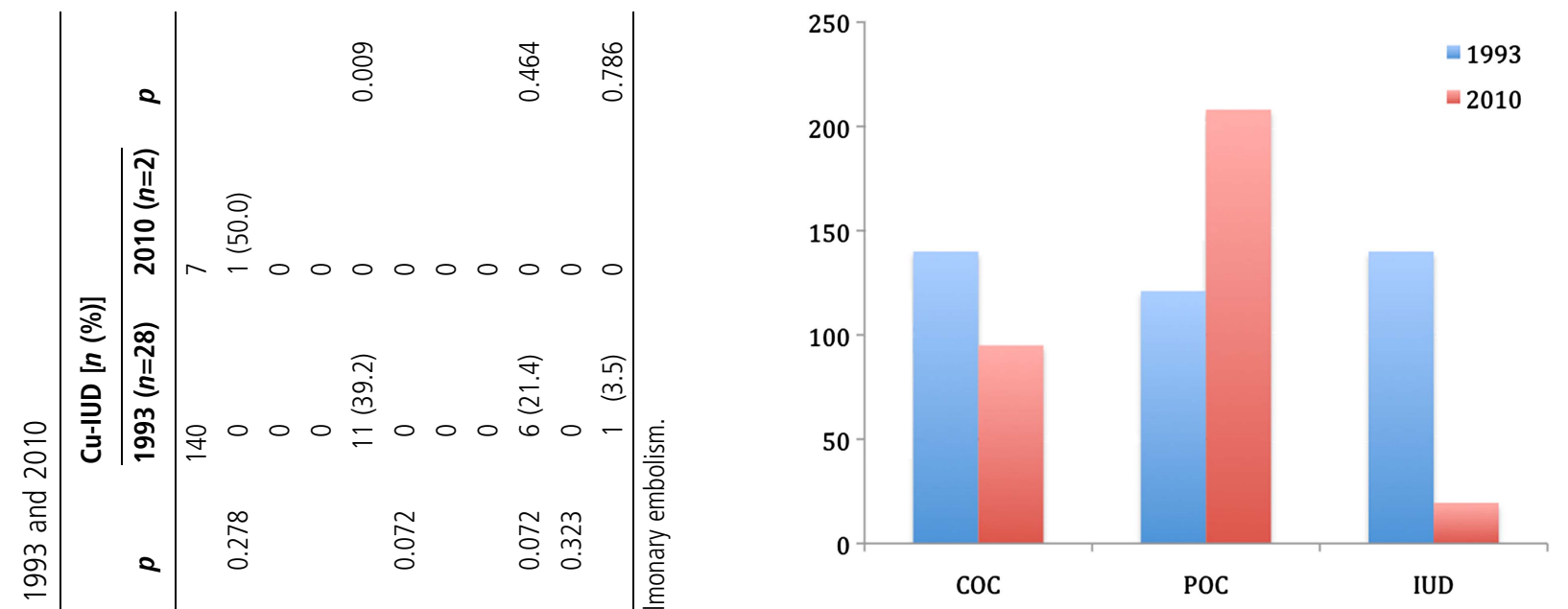

Figure 1 The woman-years of use of different contraception types in the two surveys conducted in 1993 and 2010. COC, combined oral contraceptive pill; IUD, intrauterine device; POC, progestogen-only contraceptive.

LARCs. ${ }^{26}$ DMPA use in our 2010 study is reported by $35 \%$ of SCD women, compared with 3\% for both DMPA and implants in the general population. ${ }^{26}$ However, this increased use of DMPA is supported only by the two small studies mentioned. ${ }^{24} 25$

Despite the statistically significant decline in the use of POP in women with SCD, there were still $15 \%$ of them using it compared with $5 \%$ of the general population. ${ }^{26}$ This change occurred despite there being no evidence for an increased risk of thrombosis from progestogen-only contraception in SCD. ${ }^{7}$ The 2010 survey included the relatively newer methods, the LNG-IUS and contraceptive implants. These methods together constitute $15 \%$ of the methods used in 2010 and are associated with very few reported complications. This contrasts with a marked decrease in the use of copper IUDs.

With regard to serious complications with the use of the different contraceptive methods, our data probably suggest a similar incidence of VTE with COC use in the two cohorts (two episodes during 148 womanyears in the 1993 survey, and no episodes in 98 woman-years in the 2010 survey). Taken at face value, this is higher than with hormonal contraceptive use in the general population but is in keeping with the usual incidence of VTE in women with SCD. Only one woman experienced a stroke, in the 2010 survey whilst using LARC, and it is clearly not possible to deduce any comparisons from this. Four COC users in the 1993 survey reported an increased frequency of acute sickling crises, and one COC user experienced the same problem in the 2010 survey. The rate of contraceptive failure with COC use does seem to have reduced considerably (15 failures in the 1993 survey compared with one failure in the 2010 survey). Anecdotally in the 1993 survey, the commonest reason for failure with COCs was the accidental interruption of medication during emergency hospital 
admissions. None of our data included any serious complications with POP use. However, POP use was associated with six contraceptive failures in the 1993 survey (during 77 woman-years of use), although there were none in the 2010 survey, which may reflect the introduction of the desogestrel POP and a better awareness of the potential reasons for failure with this method. The only serious complication in our data with DMPA use was one episode of VTE in the 2010 survey and there were no contraceptive failures with this method, which is consistent with DMPA's performance in the general population.

There appears also to be some progress in the number of women receiving advice against pregnancy (36\% vs 15\%). This may reflect the improving medical care of this group, and an improvement in their overall health, such that pregnancy is thought to impose less of a risk to their well being. It may also reflect a more general shift away from issuing prescriptive or prohibitive advice.

Interpretation of these data involves the inevitable problems of relatively small numbers. Information derived from the interviews with the women with SCD has potential flaws in accuracy of recall. In the 1993 survey the terms of the consent given by the women to participate precluded cross-checking against their medical records but this was permitted by the women participating in the 2010 survey. Another limitation of the present study is that we do not have full demographic information for both groups of women for comparative analysis. However, the two studies were conducted at the same centres in both 1993 and 2010. All the women participating in both studies were from black African or Afro-Caribbean ethnic groups.

All the women interviewed in both surveys felt strongly that the issues relating to pregnancy planning and contraceptive use were of high importance to them, and many of them encountered a lack of knowledge and of active discussion by their doctors of these matters. Without exception the women were enthusiastic in their participation in this research and took great trouble to provide answers to the structured questionnaire to the best of their ability.

This study highlights that health care professionals need to be better educated about the risks that women with SCD face in pregnancy and also be aware of their clear, but often unmet, need for advice about effective and safe contraception. We also note the paucity of well-conducted research investigating appropriate contraceptive options for women with SCD. Within the limitations of the data described from our research, however, we have not found any strong indication of women experiencing any particular difficulties with any of the standard methods of contraception in current use.

Acknowledgements The authors are indebted to the following haematologists who helped in registering this study at their local hospitals and allowed access to their patients: Dr Norman
Parker, Dr Bernard Davis, Dr Nerose Abdi, Dr Gavin Cho and Dr Roger Amos. They also thank Mr Ashok Kumar, Dr Lola Oni, Dr Lorna Bennet, Miss Olushola Shoyemi, Miss Vessna Graham and Miss Matty Asante-Owusu for their great support. The authors appreciate the Sickle Cell Society's help and above all the enthusiastic participation of the women with sickle cell disease. Dr Khadija Rantell carried out the trend analysis and Dr Oke Avewnagha and Dr Clara Kalu helped with the R\&D registration and in obtaining multicentre sponsorship for the study by University College London.

Competing interests None.

Ethics approval The study received ethical approval from the Cambridge 4 Research Ethics Committee on behalf of the National Multi-Centre Research Ethics Committee.

Provenance and peer review Not commissioned; externally peer reviewed.

\section{REFERENCES}

1 Streetly A, Maxwell K, Campbell B. Coordinated neonatal screening programme for haemoglobin disorders is needed. BMJ 1998;316:937.

2 Charache S, Niebyl JR. Pregnancy in sickle cell disease. Clin Haematol 1985;14:729-746.

3 Tuck SM, Studd JW, White JM. Pregnancy in sickle cell disease in the UK. Br J Obstet Gynaecol 1983;90:112-117.

4 Howard RJ, Tuck SM, Pearson TC. Pregnancy in sickle cell disease in the UK: results of a multicentre survey of the effect of prophylactic blood transfusion on maternal and fetal outcome. Br J Obstet Gynaecol 1995;102:947-951.

5 Serjeant GR, Loy LL, Crowther M, et al. Outcome of pregnancy in homozygous sickle cell disease. Obstet Gynecol 2004;103:1278-1285.

6 Wilkinson H. Saving mothers' lives. Reviewing maternal deaths to make motherhood safer: 2006-2008. BJOG 2011;118:1402-1404.

7 Haddad LB, Curtis KM, Legardy-Williams JK, et al. Contraception for individuals with sickle cell disease: a systematic review of the literature. Contraception 2012;85:527-537.

8 Cramer D, Poulter NR, Farley TMM, et al. Safety of combined oral contraceptive pills. Lancet 1996;347:546-549.

9 Jick H, Jick SS, Gurewich V, et al. Risk of idiopathic cardiovascular death and non-fatal venous thromboembolism in women using oral contraceptives with differing progestagen components. Lancet 1995;346:1589-1593.

10 Helmerhorst FM, Rosendaal FR, Vandenbroucke JP. Venous thromboembolism and the pill. The WHO technical report on cardiovascular disease and steroid hormone contraception: state-of-the-art. World Health Organization. Hum Reprod 1998;13:2981-2983.

11 Stuart MJ, Nagel RL. Sickle-cell disease. Lancet 2004;364:1343-1360.

12 Porter JB, Young L, Mackie IJ, et al. Sickle cell disorders and chronic intravascular haemolysis are associated with low plasma heparin cofactor II. Br J Haematol 1993;83:459-465.

$13 \mathrm{Kuhl} \mathrm{H}$. Effects of progestogens on haemostasis. Maturitas 1996;24:1-19.

14 Mantha S, Karp R, Raghavan V, et al. Assessing the risk of venous thromboembolic events in women taking progestin-only contraception: a meta-analysis. BMJ 2012;345:e4944.

15 Vasilakis C, Jick H, del Mar Melero-Montes M. Risk of idiopathic venous thromboembolism in users of progestogens alone. Lancet 1999;354:1610-1611. 
16 Conard J, Plu-Bureau G, Bahi N, et al. Progestogen-only contraception in women at high risk of venous thromboembolism. Contraception 2004;70:437-441.

17 Hatcher R, Rinehart W, Blackburn R, et al. The Essentials of Contraceptive Technology. Baltimore, MD: Johns Hopkins Bloomberg School of Public Health, Population Information Program, 1997.

18 Hickey M, Fraser IS. The structure of endometrial microvessels. Hum Reprod 2000;15(Suppl. 3):57-66.

19 Hickey M, Krikun G, Kodaman P, et al. Long-term progestin-only contraceptives result in reduced endometrial blood flow and oxidative stress. J Clin Endocrinol Metab 2006;91:3633-3638.

20 Lockwood CJ, Runic R, Wan L, et al. The role of tissue factor in regulating endometrial haemostasis: implications for progestin-only contraception. Hum Reprod 2000; 15(Suppl. 3):144-151.

21 Faculty of Sexual \& Reproductive Healthcare. UK Medical Eligibility Criteria for Contraceptive Use (UKMEC 2009).
2009. http://www.fsrh.org/pdfs/UKMEC2009.pdf [accessed 20 October 2013].

22 Howard RJ, Lillis C, Tuck SM. Contraceptives, counselling, and pregnancy in women with sickle cell disease. BMJ 1993;306:1735-1737.

23 Stata Corp. Stata Statistical Software: Release 11. College Station, TX: StataCorp LP, 2009.

24 De Ceulaer K, Gruber C, Hayes R, et al. Medroxyprogesterone acetate and homozygous sickle-cell disease. Lancet 1982;2:229-231.

25 de Abood M, de Castillo Z, Guerrero F, et al. Effect of Depo-Provera or Microgynon on the painful crises of sickle cell anemia patients. Contraception 1997;56: 313-316.

26 Faculty of Sexual \& Reproductive Healthcare Clinical Effectiveness Unit. Progestogen-only Implants. 2014. http:// www.fsrh.org/pdfs/CEUGuidanceProgestogenOnlyImplants.pdf [accessed 24 February 2014].

\section{Journal of Family Planning and Reproductive Health Care}

\section{Anne Szarewski Journal Memorial Award}

The Journal of Family Planning and Reproductive Health Care has established an award to commemorate the life of Anne Szarewski, our Editor-in-Chief for 10 years until her untimely death in August 2013. Anne was an inspiring journal editor, a great sexual and reproductive healthcare doctor and a pioneering researcher in the prevention of cervical cancer.

Entries for the award should take the form of a single-author article, suitable for publication in the Journal, on new initiatives or improvements in clinical practice. The author may be a nurse or midwife, a general practitioner, or a specialty trainee in sexual and reproductive healthcare or genitourinary medicine.

The award will be made annually for a period of 5 years from June 2015. In addition to publication of the winning article in the Journal, the winner will be offered the opportunity to present their work at one of the FSRH conferences during the year following the award, and will receive complimentary registration for that conference.

Full details of the award can be found on the Journal (jfprhc.bmj.com) and Faculty (www.fsrh.org) websites. 